\title{
Working
}

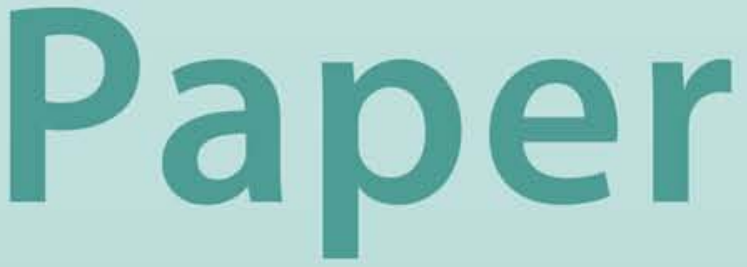


Danish for All? Balancing Flexibility with Security: The Flexicurity Model

Jianping Zhou 


\title{
IMF Working Paper
}

\author{
European Department
}

\section{Danish for All? Balancing Flexibility with Security: The Flexicurity Model}

\author{
Prepared by Jianping Zhou ${ }^{1}$
}

Authorized for distribution by Paul Hilbers

February 2007

\begin{abstract}
This Working Paper should not be reported as representing the views of the IMF. The views expressed in this Working Paper are those of the author(s) and do not necessarily represent those of the IMF or IMF policy. Working Papers describe research in progress by the author(s) and are published to elicit comments and to further debate.
\end{abstract}

The Danish flexicurity model has attracted attention among policymakers in Europe, because it suggests that a flexible labor market can coexist with a generous welfare system to achieve low unemployment. Using a panel of 19 countries over 1960-2002, the paper identifies the elements of the flexicurity model that may have contributed to the low unemployment rate. A theoretical model of dynamic policies is constructed to analyze whether the model can be emulated by other countries. Focusing on the financing aspect, the paper finds that effective implementation will depend on the initial unemployment level and budgetary situation of the country.

JEL Classification Numbers:J08, J64, C33

Keywords: Labor market reform; Unemployment; Job and income security Author’s E-Mail Address:jzhou1@imf.org

\footnotetext{
${ }^{1}$ I am grateful for helpful comments from Torben Anderson, Søren Gaard, Paul Hilbers (who suggested this topic), Ole Hollensen, Olivier Jeanne, Alessandro Leipold, Per Kongshøj Madsen, and the seminar participants at the IMF and the Danish National Bank. I would also like to thank Constanze Schulz-Calle La Rosa for excellent assistance. An early version of this paper was included as a chapter of the IMF Country Report No. 06/342, Denmark: Selected Issues, October, 2006.
} 


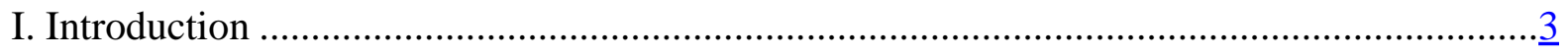

II. Key Policy Elements of the Danish Flexicurity Model............................................................

III. Unemployment Performance and the Flexicurity Model: An Empirical Analysis..............11

IV. A Model of Dynamic Policies ………………………...........................................

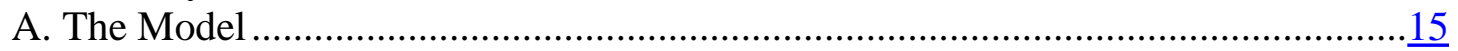

B. Model Simulations ………………………………………………………...

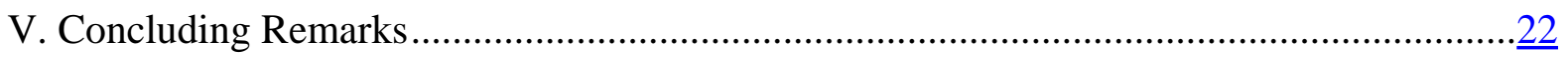

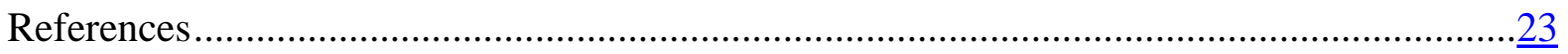

Tables

1. Estimated Equations....................................................................................................

Figures

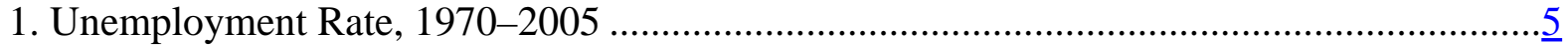

2. Strictness of Employment Protection Legislation (EPL) ...................................................

3. Unemployment Benefits ....................................................................................................

4. Key Elements of the Danish Flexicurity Model ..................................................................11

5. Unemployment Rate Convergence Toward Long-Run Equilibrium ....................................18

6. Impact of Active Labor Market Policies.........................................................................

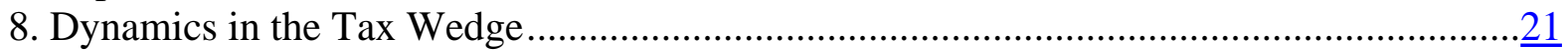

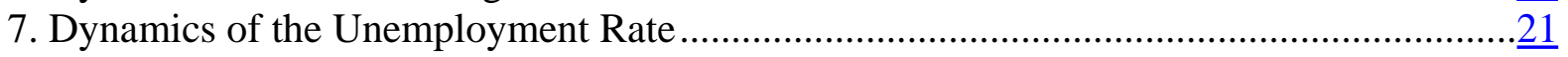

Boxes

1. Key Macroeconomic Developments..............................................................................

2. Key Labor Market Reforms .............................................................................................

3. Variables Included in the Estimations ……………….....................................................13 


\section{INTRODUCTION}

The Danish labor market model, the so-called flexicurity model, has been widely praised recently for its association with a low unemployment rate and a high standard of social security for the unemployed. ${ }^{2}$ Within this model, a high degree of labor market flexibility coexists with a high level of social protection engendered by generous unemployment benefits and active labor market policies. At a time when most European countries are facing chronically high unemployment rates but the needed labor market reforms often face strong political opposition — for fear that they can significantly erode job and income security — the Danish flexicurity model seems to suggest that this fear is unfounded and that it is possible to reduce the unemployment rate with a model that balances flexibility with security. Thus, the flexicurity model looks increasingly attractive to policymakers in Europe. At recent European Commission summits on the Lisbon strategy, member states were invited to pursue reforms in labor market and social policies under an integrated flexicurity-type approach, although without concrete guidelines as to how this integrated approach should look.

The relationship between the Danish flexicurity model and its unemployment performance, however, is not as straightforward as it seems. Denmark has traditionally had a combination of a relatively flexible labor market and a high level of income protection: Danish workers have had little protection from dismissal, but their income has been protected (Wilthagen, Frank, and van Lieshout, 2003). The economic performance under the flexicurity model has been uneven. In the early 1980s, Denmark experienced a dismal macroeconomic performance, with high and rising unemployment, high inflation, chronic current account deficits, and mounting public deficits (Box 1 and Gaard and Kieler, 2005). In the 1990s, labor market reforms were implemented to modify the flexicurity model: the maximum period for participation in active labor market programs was reduced from eight to five years in 1998 and to four years after 2000, and the eligibility criteria for unemployment benefits were tightened. As a result, the unemployment rate fell sharply during 1993-2003.

\footnotetext{
${ }^{2}$ See Schubert and Martens (2005) and Sapir (2005).
} 


\section{Box 1. Denmark: Key Macroeconomic Developments ${ }^{1 /}$}

Denmark's macroeconomic performance was rather unsatisfactory in the early 1980s. In 1982, both inflation and unemployment rose to 10 percent, growth turned negative, the budget deficit reached 9 percent of GDP, and the current account deficit peaked at 4 percent of GDP.

In 1982, the new coalition government adopted a program aiming at restructuring the economy toward the tradable sector, reducing the current account deficit, developing domestic energy resources, and reigning in public expenditures. The current account deficit was to be reduced through improvements in competitiveness and restraining domestic costs, rather than previous attempts to use exchange rate devaluations. Unemployment and sickness benefits were frozen in nominal terms, wage indexation suspended, and growth in public wages and transfer payments limited. The exchange rate was fixed within the context of the Exchange Rate Mechanism (ERM).

By the mid-1980s, inflation had dropped significantly, unemployment had fallen and stabilized, private investment had boomed, and output growth had rebalanced toward exporting industries. As additional fiscal packages, consisting mainly of energy taxes and cutbacks in public works, were adopted, the budget balance turned positive. However, in 1987, after four years of strict income policies, wage negotiations resulted in a very generous settlement. As conditions tightened, growth slowed, averaging 0.6 percent in 1987-93.

The period of slow growth ended in 1993, supported both by fiscal stimulus (a deliberately underfunded income tax cut) and monetary policy (lowered policy rates following an August 1993 speculative attack). A mix of tax and labor market reforms aimed at increasing labor participation was introduced, including required training programs for the unemployed, paid leaves for education, abolishment of an early retirement program, and the lowering of personal income taxes.

Between 1993 and 2000, Denmark enjoyed a period of rapid economic growth. Labor market reforms reinforced growth, reducing the unemployment rate to a 25-year low of 5 percent. Fiscal reforms and the growing economy transformed fiscal deficits into sizable surpluses. Public debt fell from almost 80 percent of GDP in 1993 to 45 percent by the end of the decade. As domestic savings rose and Denmark registered current account surpluses throughout the 1990s, its foreign debt position improved markedly. In 2001, however, a slowdown began as fiscal measures aimed at cooling an overheating economy held back private consumption ; meanwhile, a downturn in the global economy spilled over into net exports, and growth fell below 1 percent in 2002-03. In recent years, there was a clear revival, and growth reached more than 3 percent in 2005.
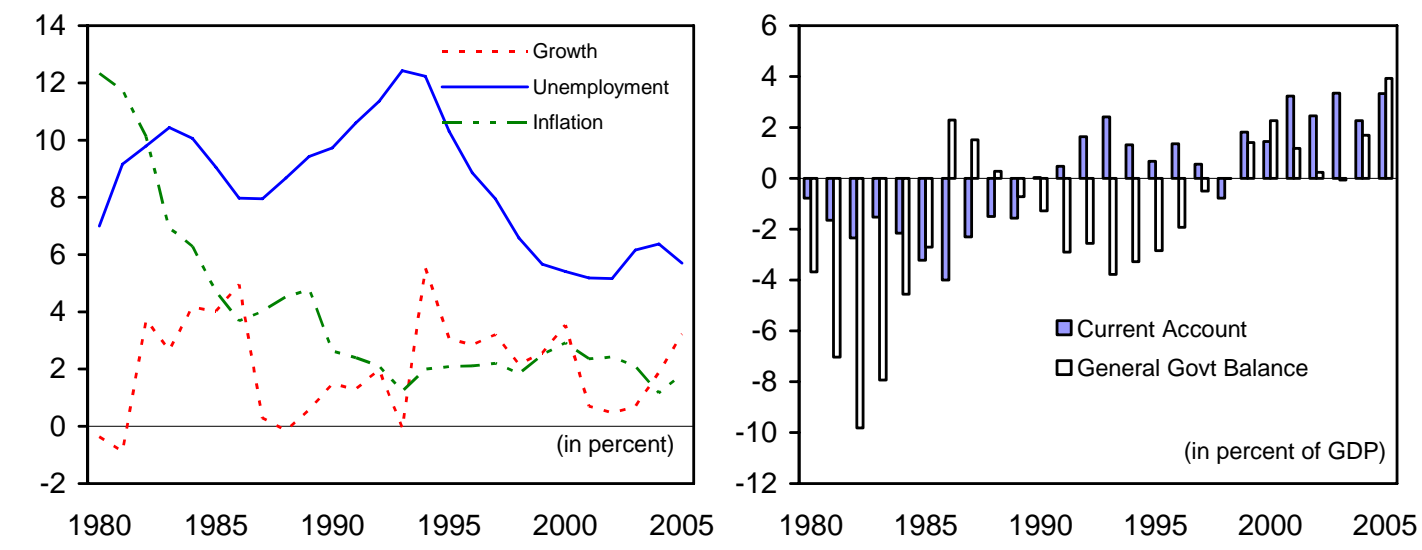

1/ See IMF Country Report No. 06/342 for further details on recent developments. 
Other countries have been able to reduce their unemployment rates to low levels with rather different social models (Figure 1). For example, Sweden, which is comparable to Denmark in terms of the size of its public sector and its generosity of the welfare system, has a more rigid labor market (as measured by the overall strictness of protection against dismissals) than Denmark but has maintained a lower unemployment rate during most of the last 30 years. Ireland and the United Kingdom, on the contrary, have achieved substantial reductions in their unemployment rates with the so-called Anglo-Saxon model, characterized by relatively low employment protection and low replacement rates.

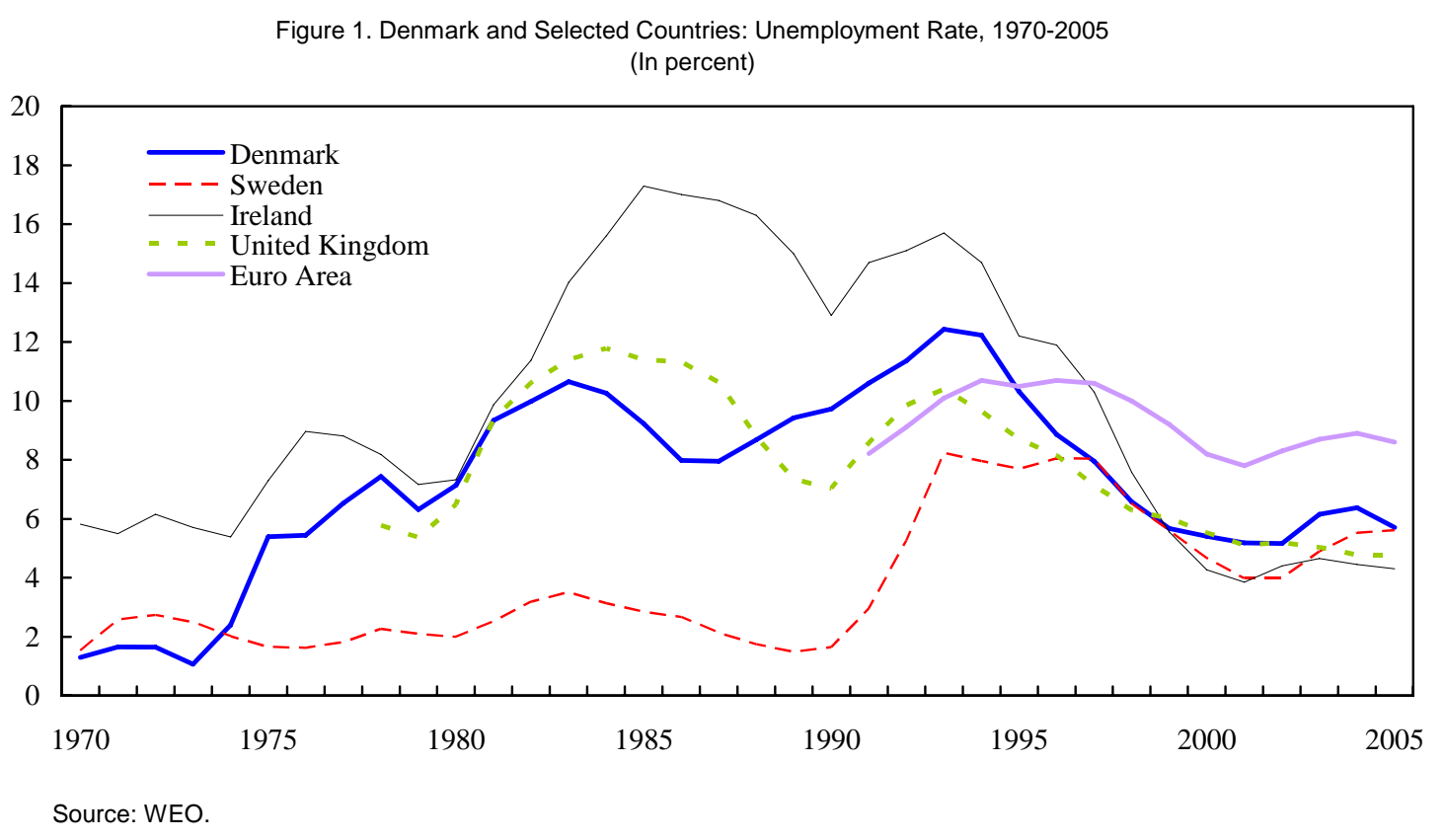

Moreover, often overlooked is the high cost of implementing the flexicurity model. Denmark has one of the largest tax wedges on labor income among European countries; this is necessary to finance its high spending on labor market programs and unemployment benefits (more than 5 percent of GDP). The following figure shows that the average tax wedge on labor income $(t w)$ for the period 1985 to 2002 exceeded 60 percent, and about 40 percent of per capita GDP was transferred to finance the average spending on active labor market programs for each unemployed (almp1). The large tax wedge reduces employment, raising the question of whether the flexicurity model efficiently combines high levels of social security and a flexible labor market. It also brings up another fundamental question: is it feasible to implement the Danish model in countries facing high unemployment rates and budgetary difficulties? 


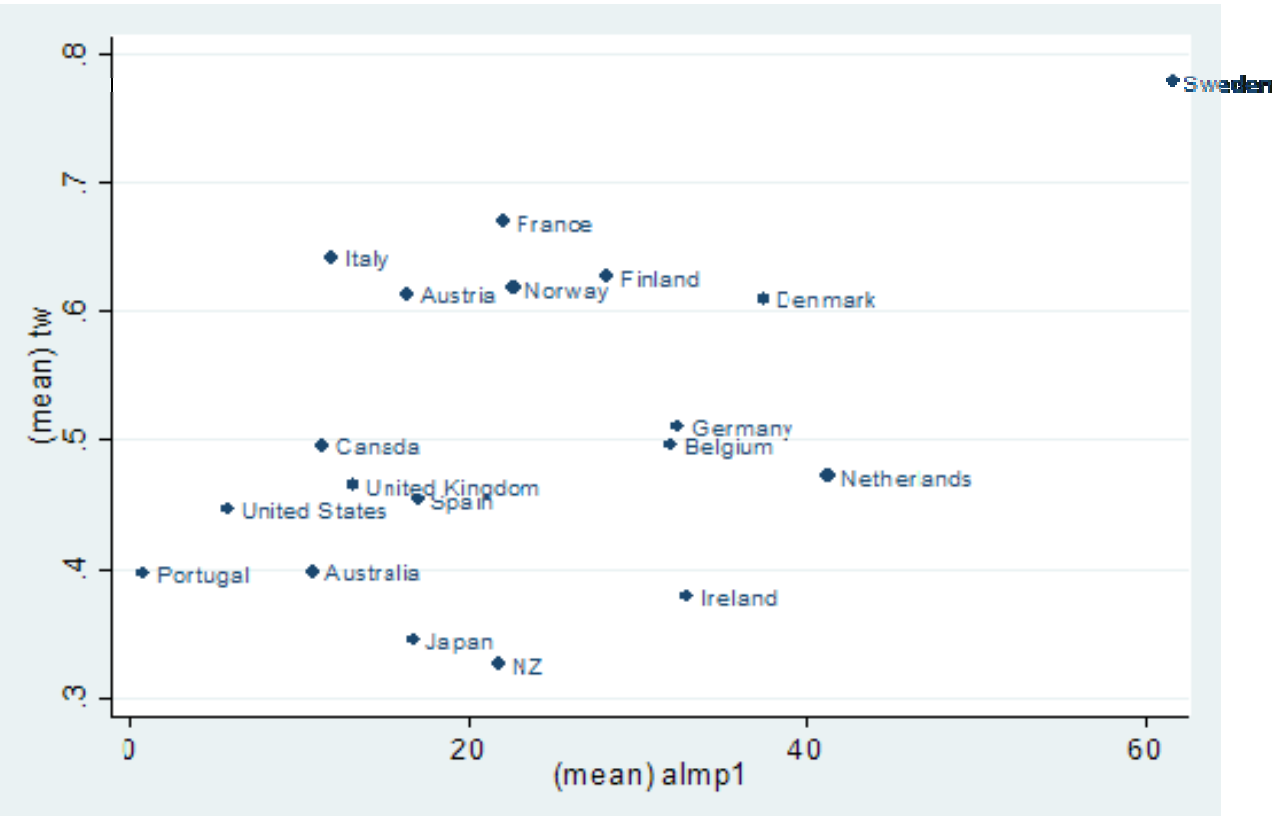

Against this background, this paper aims to answer two questions: how much of the Danish economic performance, especially with regard to unemployment, can be attributed to the flexicurity model? Can and should this model be emulated in other European countries?

Section B of this paper identifies the key policy elements of the Danish flexicurity model. Using a panel of 19 industrial countries over the period 1960-2002, Section C investigates empirically the relationship between the unemployment rate and these key policy elements. Section D sets out the theoretical model, which is applied to the French economy, to illustrate the main results of the model. Section E concludes by noting policy implications.

\section{Key Policy Elements of the Danish Flexicurity Model}

While the flexicurity model has attracted much attention in public debate, there is no clear consensus on its definition. ${ }^{3}$ In the public debate, the Danish model is often considered as part of the so-called Nordic model, which comprises the models of Denmark, Finland, Norway, and Sweden. Sapir (2005), however, categorizes the Danish model under his version of the "Nordic" model, which consists of a different set of countries (comprising Finland, the Netherlands, and Sweden). Using statistical cluster analysis, Gaard (2005) concludes that, classified by labor market regimes, the Danish model is part of the "North European" regime, which also includes the Netherlands and Sweden. Among these countries, however, there are large differences in the degree of labor market flexibility (Figure 2) and in the generosity of unemployment benefits (Figure 3). Moreover, their unemployment performances diverge as

\footnotetext{
${ }^{3}$ For example, see Gazier (2006), Madsen (2006), Bredgaard, Larsen, and Madsen (2005), and Wilthagen, Tros, and van Lieshout (2003).
} 
well. Wilthagen, Tros, and van Lieshout (2003) define the flexicurity model as a policy strategy that attempts to simultaneously enhance the flexibility of labor markets and maintain a high level of job and employment security. Bredgaard, Larsen, and Madsen (2005), however, disagree. In their view, the Danish flexicurity model is not a product of a carefully designed and deliberate strategy but the by-product of a long historical and institutional evolution and social compromises. Therefore, they doubt that it would be possible to duplicate the flexicurity model in other countries, a view also shared by Anderson and Svarer (2006).

Figure 2. Denmark and Selected Countries:

Strictness of Employment Protection Legislation (EPL)

(Higher number corresponds to stricter EPL)
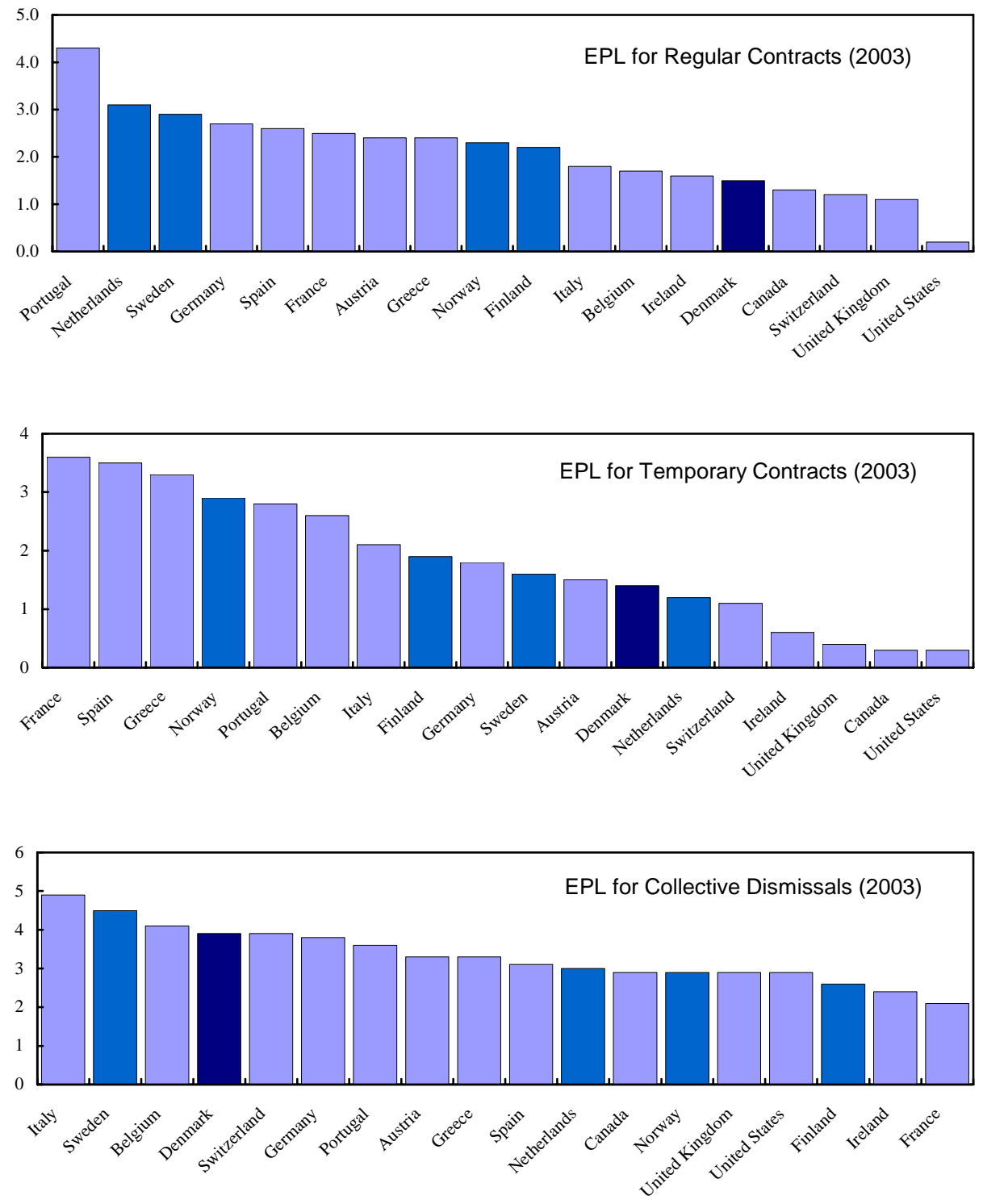

Source: OECD. 
Figure 3. Denmark and Selected Countries: Unemployment Benefits
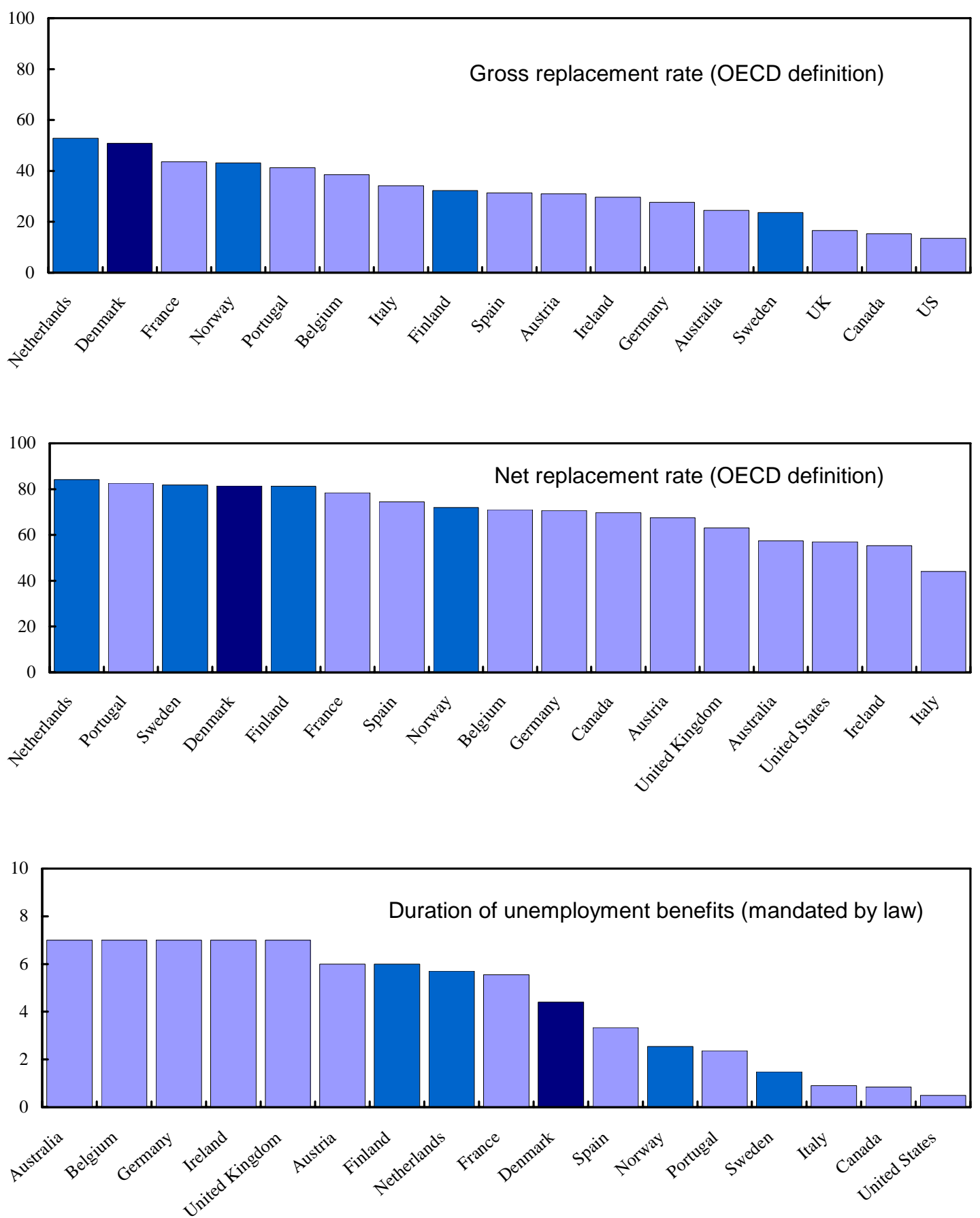

Source: Gaard (2004).

This lack of consensus exists also partly because the Danish flexicurity model has been continuously modified and fine-tuned. While this may reflect social compromises, this ongoing fine-tuning is part of the reform effort to limit the adverse employment effects of the generous social benefits system and to improve employment. Since the early 1990s, the 
government has tightened the eligibility criteria for unemployment benefits, shortened the maximum period for participation in active labor market programs, and reduced benefit durations (Box 2).

\section{Box 2. Denmark: Key Labor Market Reforms ${ }^{1 /}$}

Denmark has been undergoing major reforms of labor market policies since 1993. The initial emphasis was placed on sabbatical leave and other job rotation schemes that tended to lower participation rates. The employment effect was limited. The emphasis has subsequently shifted to strengthening work incentives and enhancing employability. Although benefits have remained generous, reflecting the priority that the government attaches to preserving a fairly egalitarian distribution of income, the reforms have been associated with reductions in structural unemployment, particularly for the young and longterm unemployed.

Since the end-1990s, the authorities have introduced further measures to improve the functioning of the labor market. Apart from the income tax reform, which will gradually lower the marginal tax rates on labor incomes, labor market measures include the following:

- $\quad$ Unemployed are now obliged to accept job offers outside their occupational area after three months of receiving unemployment benefit;

- $\quad$ The mandatory “activation” of the unemployed after six months of unemployment was extended to all persons under 25; failure to activate (i.e., to accept a job or a placement in a training/retraining scheme) entails a complete loss of benefits;

- $\quad$ The minimum age for extended benefits was raised from 50 to 55 years;

- $\quad$ The maximum unemployment benefit period was reduced from five to four years;

- $\quad$ Training for the unemployed has become more targeted, and participation in educational leave schemes has become more restrictive;

- $\quad$ The full- and part-time early retirement schemes were merged, creating a more flexible, unified, and ostensibly more transparent system;

- $\quad$ Tax and benefit incentives were given to prolong full-time working life until 62 years of age; these include, among others, larger tax deductibles "earned" by working until an older age and a change in the payment profile of early retirement benefits; and

- $\quad$ Income incentives were enhanced to discourage early retirement.

The welfare agreement of June 2006 unveiled, among others, proposals to further reduce the time limit for activation from one year to six months and abolish the extended entitlement period for the 50-55 age group.

1/ IMF country reports on Denmark.

Any assessment of the flexicurity model would require a breakdown of labor market flexibility and social security into their various components. Wilthagen, Tros, and van Lieshout (2003) offer a useful approach. In their framework, labor market flexibility consists of one or a combination of the following four dimensions: 
- $\quad$ external flexibility (e.g., flexibility of hiring and firing);

- $\quad$ internal flexibility (e.g., flexibility of working hours, overtime, and part-time work);

- $\quad$ functional flexibility (e.g., possibility of holding more than one job and flexible organization of work); and

- $\quad$ wage flexibility (e.g., the absence of binding minimum wages or wage indexation).

Similarly, social security involves the following four elements:

- $\quad$ job security (high probability of retaining one’s current job);

- $\quad$ employment security (high probability of finding another job quickly in case of a layoff);

- $\quad$ income security (income protection in the event of job loss); and

- “ combination" security (the ability to combine paid work with other social responsibilities and obligations). ${ }^{4}$

While their approach provides a systematic way to study the social models that have been adopted in European countries in various forms and their evolution over time, it does not always distinguish policies from outcomes. Moreover, some of the policy elements are difficult to quantify.

The analysis in this paper is based on the framework discussed above but attempts to more clearly distinguish policies from outcomes. This is particularly important when assessing whether the Danish model can be copied by other countries. Given certain data limitations, this study focuses on the following policies and institutions providing labor market flexibility and security for the unemployed:

- $\quad$ few restrictions on hiring and firing (external flexibility);

- $\quad$ a wage-setting and bargaining framework conducive to wage flexibility;

- $\quad$ a high level of unemployment benefits (providing income security); and

- $\quad$ active labor market policies (providing employment security).

These policies and institutions can be quantified using the data sets from the OECD and Gaard (2005).

Based on these quantified policy indicators, four key features of the Danish flexicurity model are the focus of this paper (Figure 4). First, a very flexible labor market: measured by the

\footnotetext{
${ }^{4}$ This can be seen as job flexibility from the workers' perspective-for example, the possibility to take longterm maternity leave with the guarantee of reemployment. In this context, this type of security can be key to female participation and employment.
} 
restrictiveness of employment protection legislation, the Danish labor market is more flexible than many other European countries. Second, generous unemployment benefits: the average net replacement rate, at about 80 percent, is among the highest in Europe. Third, high spending on active labor market programs: average spending on active labor market programs per unemployed is also one of the highest. Finally, a large tax wedge on labor income: the flexicurity model is costly. ${ }^{5}$

Figure 4. Denmark and Selected Countries: Key Elements of the Danish Flexicurity Model
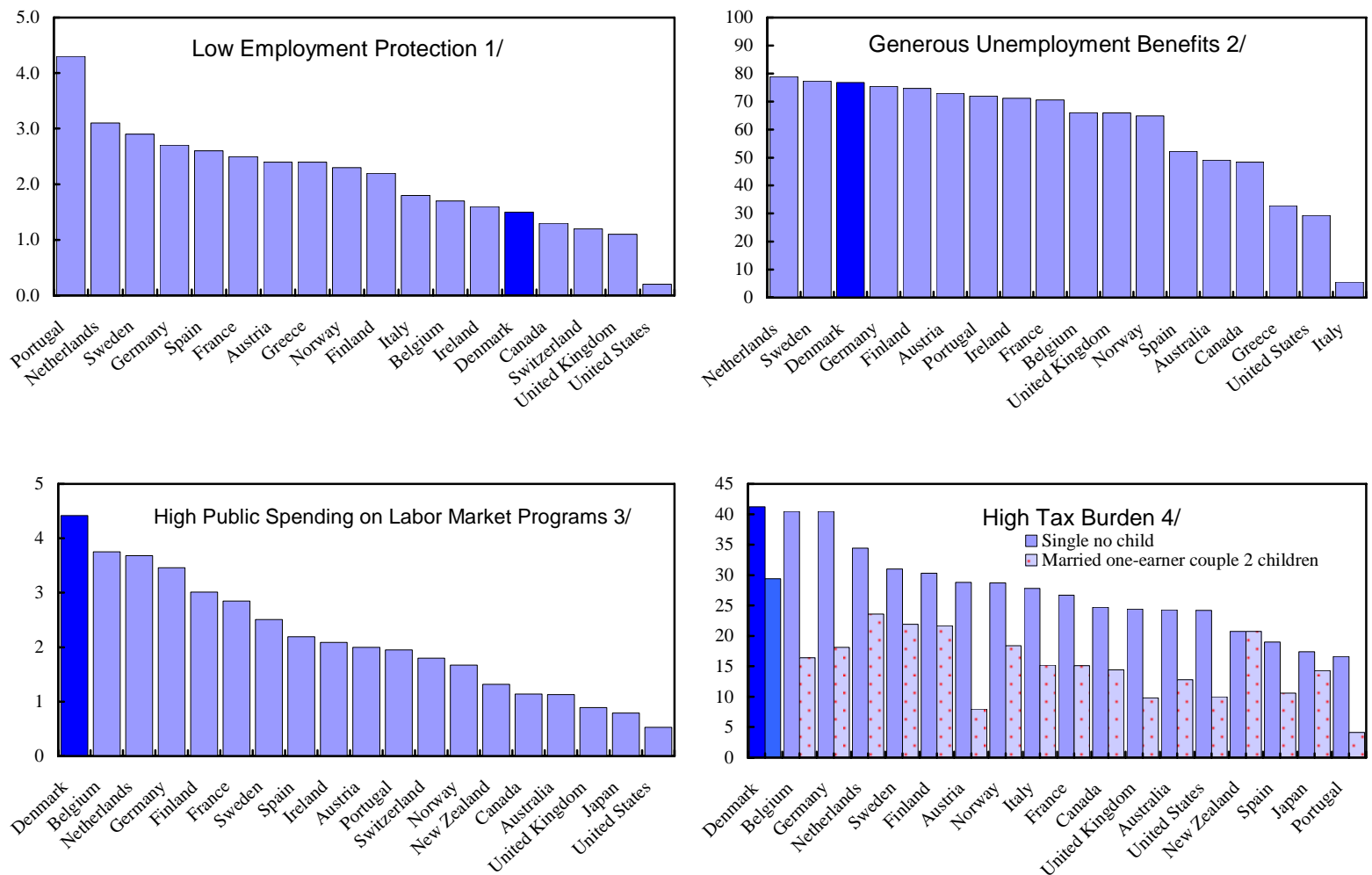

Source: OECD.

1/ OECD index on employment protection legislation (EPL) for regular jobs (2003). Higher numbers indicate stricter EPL. 2/ Average net replacement rate over 5 years of unemployment and includes social benefits (2004). 3/ In percent of GDP (2003).

4/ Income tax plus employee contributions less cash benefits, as percent of gross wages (2004).

\section{UNEMPLOYMENT PERFORMANCE AND THE FLEXICURITY MODEL: AN EMPIRICAL ANALYSIS}

The Danish flexicurity model has attracted attention, in particular because it has been associated with a low unemployment rate, now below 5 percent. For the workers, a low unemployment rate augments the income security from generous unemployment benefits

\footnotetext{
${ }^{5}$ It should be noted that adding the social security contributions by employers (SSCs) would further raise the tax wedge, but more so for some other countries, as SSCs in Denmark are relatively low.
} 
with a perception of employment security (i.e., there is a high probability of finding another job quickly in case of a layoff). A low unemployment rate is also important for the financial viability of the flexicurity system - it ensures that the cost of labor market policies remains sustainable and that the tax wedge does not widen excessively.

It is therefore key to assess how various policy elements of the flexicurity model may have contributed to the low unemployment rate in Denmark. The advocates of this model claim that the reduction in the unemployment rate since 1993 is due to the flexibility in the labor market and the active labor market policies, which more than offset the negative impact of the high labor taxes on employment. Is this claim supported by cross-country evidence? How much of the reduction in unemployment was attributable to the active labor market policies?

The purpose of the empirical exercise is to identify the policy elements of the flexicurity model that are significantly correlated to the unemployment rate. The basic empirical work consists of running cross-country panel regressions of the following equation:

$$
u m_{i t}=\alpha_{0}+\alpha_{i}+\tau_{i}+\sum_{j} \beta_{j} x_{j i t}+\sum_{k} \beta_{k} y_{k i t}+\sum_{l} \beta_{l} z_{l i t}+\lambda \cdot c y c l e+v_{i t},
$$

where $I=$ country index; $t=$ year; $x_{j}=$ policy variables contributing to labor market flexibility; $y_{k}=$ policy variables contributing to income security; $z_{l}=$ active labor market policy variables; $\alpha_{0}$ is a constant term; $\alpha_{i}$ captures the unexplained country-specific effect; $\tau_{i}$ is the country-specific time trend; and $v_{i t}$ is the error term. The panel consists of 15 countries over the period 1980 to 2004. The list of variables included in the estimations is presented in Box 3. The empirical analysis assumes that the equilibrium unemployment rate is influenced by the set of policy elements of the flexicurity model, which are the focus of this paper. The analysis also controls for the cycle and other unexplained country- and timespecific effects.

Specifically, we estimate four equations. Equation (1) is based on the specification in Gaard (2005), while Equation (2) includes year dummies to capture interactions between policy variables and common shocks. Equation (3) aims to reproduce the results in Blanchard and Wolfers (2000). Finally, Equation (4) introduces a lagged dependent variable to capture both the short- and long-run unemployment impact of policy variables. 
Box 3. Denmark: Variables Included in the Estimations

Policy elements of the flexicurity model that determine labor market flexibility:

- $\quad$ employment protection legislation (EPL): OECD or World Bank indicators on the strictness of EPL;

- $\quad$ wage-setting institutions that determine wage flexibility: wage-setting institutions, trade union density, and collective bargaining coverage (OECD data); and

- $\quad$ other measures of wage flexibility: wage compression (trend in earnings dispersion 1980-2001, OECD data).

Policy elements of the flexicurity model that determine social security:

- $\quad$ generosity of unemployment benefits: the average of unemployment compensation rates (gross) for two income levels and three family types over a five-year period (OECD data);

- $\quad$ gross and net replacement ratio: Gaard (2005);

- $\quad$ duration of benefits: (1) legal durations; and (2) index constructed from gross unemployment benefits over five years (Gaard, 2005);

- $\quad$ active labor market policies: expenditure on active labor market policies (ALMP) (OECD data, 1980-2003); and

- $\quad$ employment enforcement: index calculated by Gaard (2005).

Costs and financing of the flexicurity model:

- $\quad$ tax wedge: OECD data on labor taxes; and

- $\quad$ total public spending on labor market programs: OECD data.

Macroeconomic variables:

- $\quad$ business cycle: logarithm of demeaned GDP (in volume); and

- output gaps.

In addition, an index of product market deregulation (OECD data) is used.

The empirical results are largely consistent with predictions based on existing theories and the findings of other studies (Table 1). Generous unemployment benefits (as measured by the replacement rate) tend to increase the structural unemployment rate by reducing incentives to work and raising reservation wages. A large tax wedge on labor income is likely to also increase the unemployment rate through its negative effect on labor demand, as well as on labor supply. However, a flexible labor market (as measured by less strict EPLs and institutions supporting wage flexibility) helps reduce the structural unemployment rate by improving labor market dynamics. Indeed, there is empirical evidence that countries with stricter EPLs tend to have a higher unemployment persistence. Moreover, the EPLs could 
have a significant influence on how the unemployment rate adjusts to shocks (Blanchard and Wolfers, 2000). We found that active labor market policies contribute to low structural unemployment rates, which is consistent with the findings of other empirical studies. ${ }^{6}$ However, this may be partly due to a well-recognized statistical problem: participants in active labor market programs are considered as employed.

Table 1. Denmark: Estimated Equations

\begin{tabular}{|c|c|c|c|c|}
\hline Dependent variable: $\mathrm{u}(\mathrm{t})$ & Equation 11 / & Equation 2 2/ & Equation $33 /$ & Equation 4 \\
\hline \multirow[t]{2}{*}{$\mathrm{u}(\mathrm{t}-1)$} & & & & $0.6910 * \star \star$ \\
\hline & & & & 0.0439 \\
\hline \multirow[t]{2}{*}{ Expenditure on ALMP } & $-0.0011 * \star *$ & $-0.0011 * \star \star$ & $0.0011 * \star \star$ & $0.0004 * * *$ \\
\hline & 0.0001 & 0.0001 & 0.0001 & 0.0001 \\
\hline \multirow[t]{2}{*}{ EPL } & 0.0006 & 0.0014 & 0.1850 & 0.0096 \\
\hline & 0.0080 & 0.0106 & 0.0107 & 0.0005 \\
\hline \multirow[t]{2}{*}{ Overall gross replacement rate } & $0.0015 * \star \star$ & $0.0017 * \star \star$ & $0.0030 \star \star \star$ & 0.0002 \\
\hline & 0.0004 & 0.0003 & 0.0004 & 0.0004 \\
\hline \multirow[t]{2}{*}{ Benefit duration } & & & 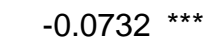 & \\
\hline & & & 0.0146 & \\
\hline \multirow[t]{2}{*}{ Total tax on labor } & 0.0244 & 0.0339 & 0.0524 & 0.0070 \\
\hline & 0.0361 & 0.0361 & 0.0297 & 0.0221 \\
\hline \multirow[t]{2}{*}{ Availability requirement } & -0.0137 & -0.0225 & & \\
\hline & 0.0203 & 0.0211 & & \\
\hline \multirow[t]{2}{*}{ Centralization of wage negotiations } & 0.0015 & -0.0023 & 0.0023 & \\
\hline & 0.0041 & 0.0041 & 0.0037 & \\
\hline \multirow[t]{2}{*}{ Union density } & $0.1445 * \star \star$ & 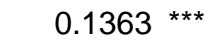 & 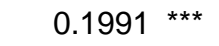 & $0.0709 * * \star$ \\
\hline & 0.0242 & 0.0255 & 0.0275 & 0.0200 \\
\hline \multirow[t]{2}{*}{ Output gaps } & $-0.6889 \star \star \star *$ & $-0.0309 \star \star \star$ & & $-0.0436 * * *$ \\
\hline & 0.0153 & 0.0171 & & 0.0100 \\
\hline NOB & 230 & 230 & 230 & 236 \\
\hline R-sq: Within & 0.60 & 0.67 & 0.71 & 0.81 \\
\hline Between & 0.01 & 0.01 & 0.01 & 0.66 \\
\hline Overall & 0.01 & 0.02 & 0.01 & 0.70 \\
\hline
\end{tabular}

Source: IMF staff estimates.

1/ Based on the specification in Gaard (2005).

2/ Equation 1 with time dummies that aim to capture common shocks.

3/ Based on the model specification in Blanchard and Wolfer (2000).

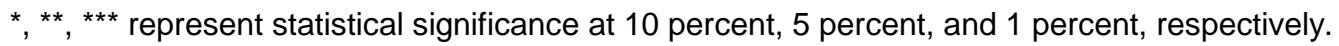

\footnotetext{
${ }^{6}$ Gaard (2005), Blanchard and Wolfers (2000), Estevão (2003), and Scarpetta (1996).
} 


\section{A Model of Dynamic Policies}

Can the Danish model be emulated by other European countries to reduce unemployment? Specifically, can a social model that combines labor market flexibility with generous unemployment insurance and active labor market policies, as we observe in Denmark, be implemented in these countries? The answer is not obvious. For example, Algan and Cahuc (2005) argue that the continental and Mediterranean European countries are unlikely to be able to implement the Danish model because of the lack of "public-spiritedness" of their citizens; in other words, the flexicurity model is hardly sustainable in these countries because generous unemployment benefits raise moral hazard issues that hinder effective implementation. There is also the issue of optimal sequencing in the introduction of the different components of the Danish policy mix. Should the flexibility be introduced before the other policies? Should the other policies be phased in contingent on progress in reducing unemployment? If the initial steps of the reform involve more flexibility than security, is there a way of making it credible to the workers that the reform plan is not simply about “flexibility without security”?

The theoretical model in this paper centers on the financing aspect of the flexicurity model and its negative effect on employment. A key feature of the Danish model is its high spending per unemployed, financed through a large tax wedge on labor income. As most countries that are tempted to adopt the Danish model will typically start from a high unemployment level (this is generally why they are considering changing their policies), a move toward the Danish model will, in the short run, trigger a sharp increase in the cost of unemployment benefits and active labor market policies, thereby widening the tax wedge, with an adverse impact on labor demand and supply. ${ }^{7}$

\section{A. The Model}

The model consists of two equations: Equation (1) characterizes the dynamics of unemployment as a function of policies:

$$
u_{t}=c+\rho u_{t-1}-\alpha a \operatorname{almp}_{t}+\beta p \operatorname{plmp}_{t}+\gamma e p l_{t}+\delta t w_{t},
$$

where $u_{t}$ is the structural unemployment rate; $\operatorname{almp}_{t}$ is the public expenditure on active labor market policies per unemployed worker (expressed as a share of the average wage); $\operatorname{lmp}_{t}$ is the public expenditure on passive labor market policies (i.e., unemployment benefits) per unemployed worker (expressed as a share of the average wage); $e p l_{t}$ is a measure of the strictness of employment protection legislation; and $t w_{t}$ is the tax wedge. All coefficients are positive.

\footnotetext{
${ }^{7}$ It is assumed that a large part of the funding comes from labor income taxation and social security contributions, which widen the wedge.
} 
Equation (2) gives the budget constraint: any increase in the expenditure on active or passive labor market policies is financed by a rise in taxes on labor income:

$$
\left(1-u_{t}\right) L_{t} W_{t} t w_{t}=\left(1-u_{t}\right) L_{t} W_{t} \phi+u_{t} L_{t} W_{t}\left(a \lim p_{t}+p \operatorname{lmp} p_{t}\right)
$$

The left-hand side of the equation is the income from imposing the tax $t w_{t}$ on the wage income $\left(1-u_{t}\right) L_{t} W_{t}$, where $L_{t}$ is the labor force and $W_{t}$ is the average wage. The right-hand side of the equation represents the cost of the labor market policies.

Result 1. The fiscal impact of increasing active or passive labor market policies depends on the level of the unemployment rate.

This can be shown by rewriting Equation (2) as

$$
t w_{t}=\phi+\frac{u_{t}}{1-u_{t}}\left(a \operatorname{lmp} p_{t}+p \operatorname{lmp} p_{t}\right)
$$

Taking the derivative of Equation (3) gives

$$
\frac{\partial t w_{t}}{\partial a \operatorname{lm} p_{t}}=\frac{\partial t w_{t}}{\partial p \operatorname{lm} p_{t}}=\frac{u_{t}}{1-u_{t}},
$$

which implies that the fiscal impact increases more than proportionately with the unemployment level. For example, the impact of a given change in labor market policies in a country with an initial unemployment rate of 10 percent is 2.1 times higher than that in a country with an unemployment rate of 5 percent.

The long-run steady-state relationship between the policies and the unemployment rate is obtained by setting $u_{t}=u_{t-1}$ :

$$
(1-\rho) u=c+\delta \phi-\alpha \operatorname{alm} p+\beta p \operatorname{lm} p+\gamma e p l+\delta \frac{u}{1-u}(\operatorname{alm} p+p \operatorname{lm} p)
$$

This can be written as a second-order equation for the unemployment rate:

$$
u^{2}-\lambda u+\kappa=0
$$

with

$$
\begin{gathered}
\lambda=1+\frac{c+\delta \phi-(\alpha+\delta) a \operatorname{lmp}+(\beta-\delta) p \operatorname{lm} p_{t}+\gamma e p l}{1-\rho}, \text { and } \\
\kappa=\frac{c+\delta \phi-\alpha \operatorname{alm} p+\beta p \operatorname{lm} p+\gamma e p l}{1-\rho}
\end{gathered}
$$


The steady-state unemployment rate is given by

$$
u=\frac{\lambda \pm \sqrt{\lambda^{2}-4 u}}{2}
$$

Result 2. There could be two equilibrium unemployment rates for a given set of policies: a "good equilibrium" associated with a low unemployment rate and a small tax wedge, and a "bad equilibrium" associated with a high unemployment rate and a large tax wedge. Only the low-unemployment equilibrium is stable.

The multiple equilibriums are the result of the two-way causality between the level of the unemployment rate and that of the tax wedge. A large tax wedge tends to reduce employment and increase unemployment, resulting in higher spending on unemployment benefits, which will likely result in an even larger tax wedge on labor income.

To prove that only the low-unemployment equilibrium is stable, using Equations (1) and (3), we can obtain

$$
u_{t}^{2}-\left(\eta+\rho u_{t-1}\right) u_{t}+\rho u_{t-1}+\eta-1+\delta\left(a \operatorname{lm} p_{t}+p \operatorname{lmp} p_{t}\right)=0
$$

where

$$
\eta=1+c+\delta \phi-(\alpha+\delta) a l m p_{t}+(\beta-\delta) p \operatorname{lmp}_{t}+\gamma e p l_{t}
$$

By differentiating Equation (5), we can obtain the first derivative of the period $t$ unemployment rate with respect to the previous period's unemployment rate:

$$
\frac{\partial u_{t}}{\partial u_{t-1}}=\frac{\rho}{1-\delta\left(a \operatorname{lmp} p_{t}+p \operatorname{lmp} p_{t}\right) /\left(1-u_{t}\right)^{2}} .
$$

Since $\partial u_{t} / \partial u_{t-1}$ is increasing with $u_{t}$, this implies that if there are two equilibriums, the one with the higher rate of unemployment is unstable because $\partial u_{t} / \partial u_{t-1}>1$. The stable long-run equilibrium rate is

$$
u^{*}=\frac{\lambda-\sqrt{\lambda^{2}-4 u}}{2}
$$

and the unemployment rate $u_{t}$ converges toward $u^{*}$ (Figure 5), provided that it is initially lower than 


$$
u^{* *}=\frac{\lambda+\sqrt{\lambda^{2}-4 u}}{2} .
$$

Figure 5. Denmark: Unemployment Rate Convergence Toward Long-Run Equilibrium

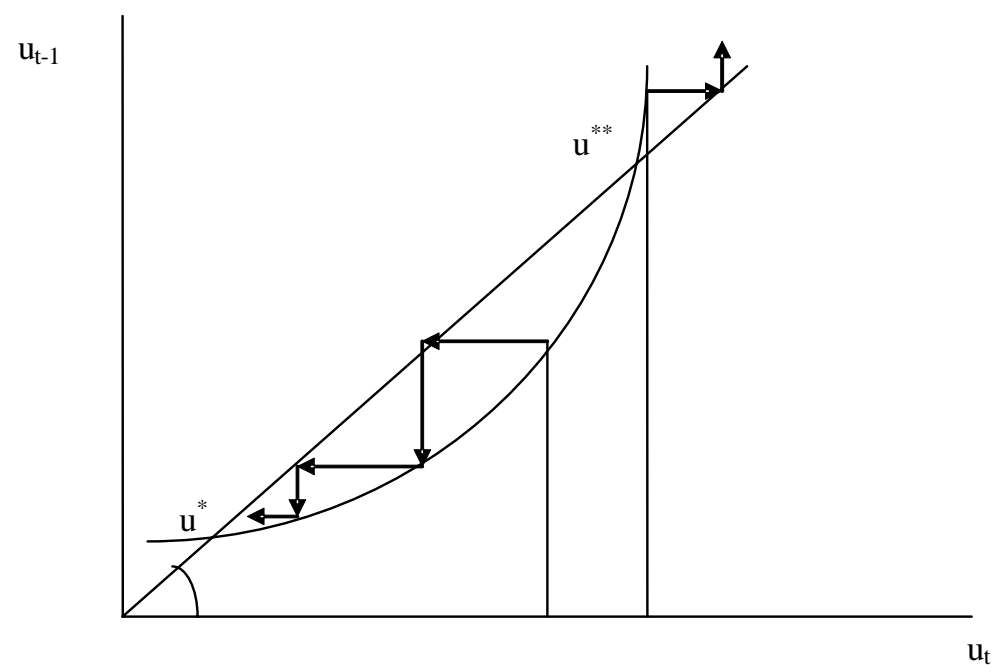

Result 3. The impact of active labor market policies depends on a country's initial level of unemployment and the level of the tax wedge: the unemployment rate declines in a country with a low unemployment rate and a low tax rate but rises in a country with high unemployment and a large tax wedge.

This is illustrated by Figure 6. The horizontal line captures the right-hand side of the following equation determined by policy variables:

$$
\left[(1-\rho)-\frac{\delta}{1-u}(\operatorname{almp}+p \operatorname{lmp})\right] u=c+\delta \phi-\alpha \operatorname{almp}+\beta \text { plmp }+\gamma \text { epl } .
$$

The concave curve captures the left-hand side of the equation, which is influenced by the level of the unemployment rate. An increase in spending on active labor market programs will shift the horizontal line downward. It has opposite effects on the unemployment rate: it falls in the "good" equilibrium but rises in the "bad" equilibrium. This is mainly because of the dynamics among active labor market policies, taxes, and unemployment rates. In the case where $\delta=0$ (i.e., when higher spending on active labor market programs is not financed by higher taxes), the concave curve becomes a straight line, and active labor market policies would only lower the unemployment rate. 
Figure 6. Denmark: Impact of Active Labor Market Policies

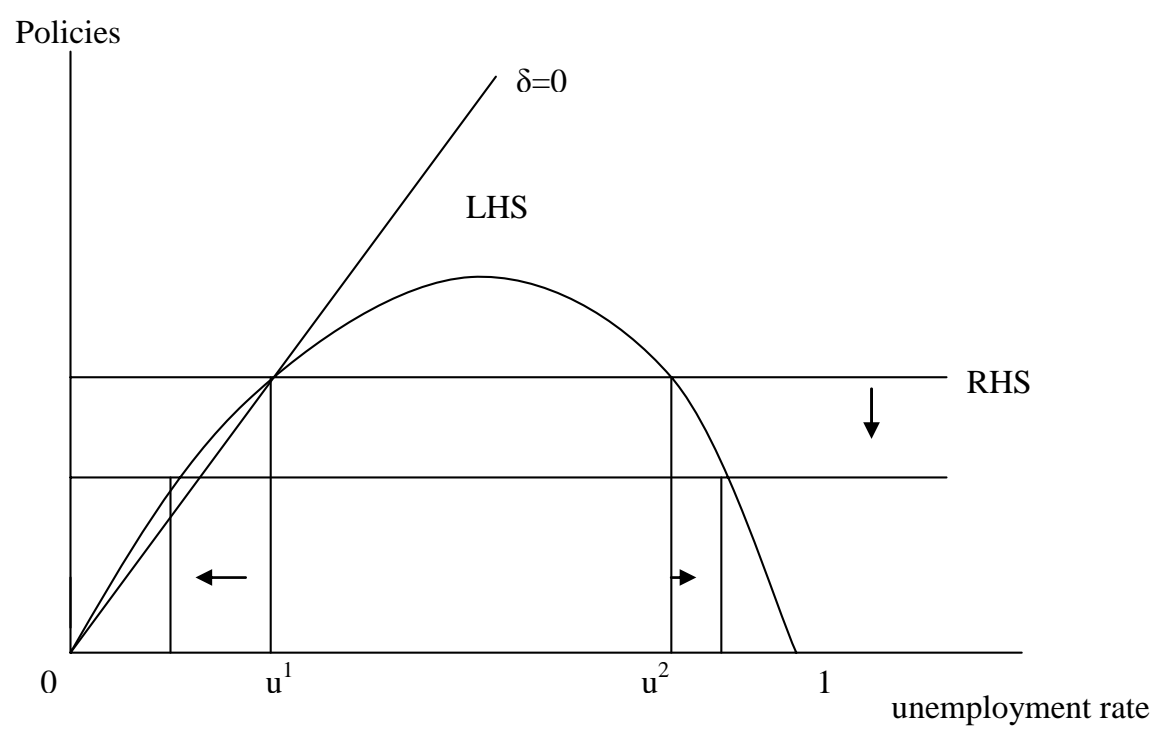

B. Model Simulations

In this section, we calibrate the theoretical model to simulate the policy effects discussed in the previous section. By doing so, we hope to shed light on the impact of a real-world experiment of transposing the Danish model to other countries. Specifically, we consider a country starting from a steady state with a constant unemployment rate $u_{0}$ and constant policies almp $0, p l m p_{0}, e p l_{0}$, and $t w_{0}$. In period 1, a permanent change in the country's policies takes place. The policies become

$$
\begin{aligned}
& a \operatorname{alm} p_{1}=\operatorname{almp}_{0}+\Delta a \operatorname{lmp}, \\
& \operatorname{plmp}_{1}=p \operatorname{lm} p_{0}+\Delta p \operatorname{lmp}, \text { and } \\
& e \mathrm{el}_{1}=e p l_{0}+\Delta e p l,
\end{aligned}
$$

in period 1 and all the following periods $t>1$. The question is how unemployment rate and the tax wedge respond to the policy change, taking into account the endogeneity of the tax wedge to unemployment and that of unemployment to the tax wedge.

The basic assumption is that the structural equation capturing the long-run steady-state relationship between the policies and the unemployment rate apply to all countries and that cross-country differences in the unemployment rate result from differences in policies. The dynamic equation of the unemployment rate for simulation can be solved as

$$
u_{t}=\frac{1}{2}\left[\eta+\rho u_{t-1}-\sqrt{\left(\eta+\rho u_{t-1}\right)^{2}-4\left(\eta+\rho u_{t-1}+\delta(\operatorname{almp}+p \operatorname{lm} p)\right.}\right] .
$$


The dynamics of the unemployment rate can then be derived by iterating this equation starting from an initial level $u_{0}$.

As an example, the model has been calibrated for France. France has a relatively high unemployment rate and a large tax wedge on labor income (Zhou, 2006). For the simulation, the following parameters have been used, based on the existing literature, as well as on our own empirical analysis:

\begin{tabular}{rrrrrr}
$c$ & $\rho$ & $\alpha$ & $\beta$ & $\delta$ & $\varnothing$ \\
\hline 0.0014 & 0.9 & 0.01 & 0.01 & 0.01 & 0.6
\end{tabular}

The initial conditions are given by

$$
\begin{aligned}
& \operatorname{almp}_{0}=0.32, \\
& \operatorname{plmp}_{0}=0.40 \text {, and } \\
& t w_{0}=0.68 .
\end{aligned}
$$

The variables are expressed as a fraction of 1 (not in percentage points). For example, $t w=$ 0.68 means the tax wedge is 68 percent. The initial steady-state unemployment rate is 9 percent $\left(u_{0}=0.09\right)$.

We consider a reform scenario where the spending on active labor programs is increased to the level in Denmark $\left(a \operatorname{lmp} p_{1}=0.55\right)$. The simulation results are shown in Figures 7 and 8. Two interesting results emerge:

- $\quad$ The immediate impact of the reform is fairly small. While the steady-state unemployment rate will be reduced to 6.9 percent eventually, the adjustment process is very slow; for example, it takes seven years to reduce the unemployment rate by 1 percent. This is partly because the unemployment rate is relatively persistent in France, which may result from, among other factors, the strict regulations on hiring and firing.

- $\quad$ The reform is costly. The tax wedge would widen at the time of the reform to 70 percent to finance the higher spending on active labor market programs; in the model, it takes more than 20 years for the tax wedge to return to its prereform level.

Under this simulation, the employment effect of the tax wedge turns out to be rather small. What dominates the dynamics is the slow speed of adjustment of the unemployment rate, which is influenced by labor market rigidities and other rigidities in the product market. This finding reinforces the importance of flexible labor markets. 
Figure 7. France: Dynamics of the Unemployment Rate (In percent)

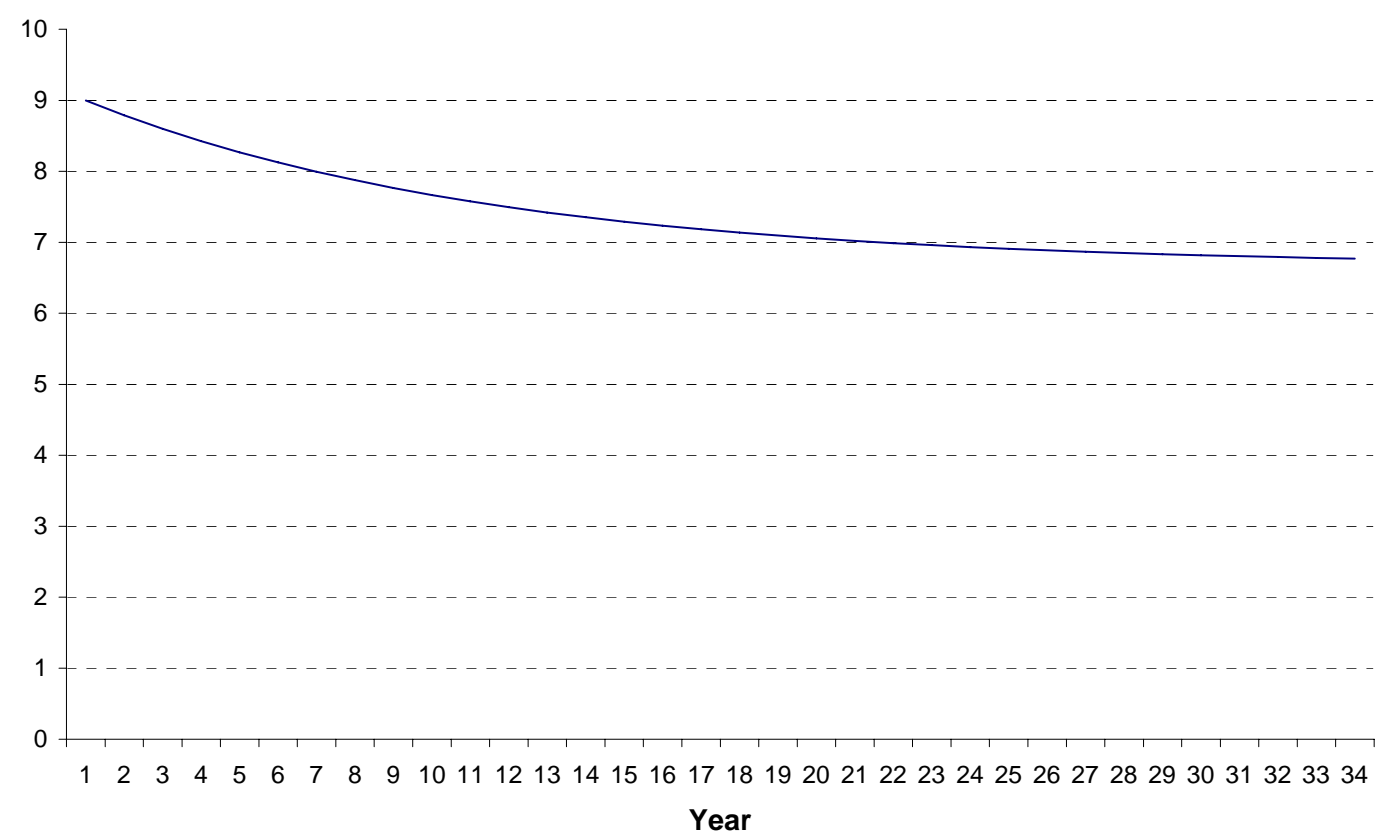

Figure 8. France: Dynamics of the Tax Wedge (In percent)

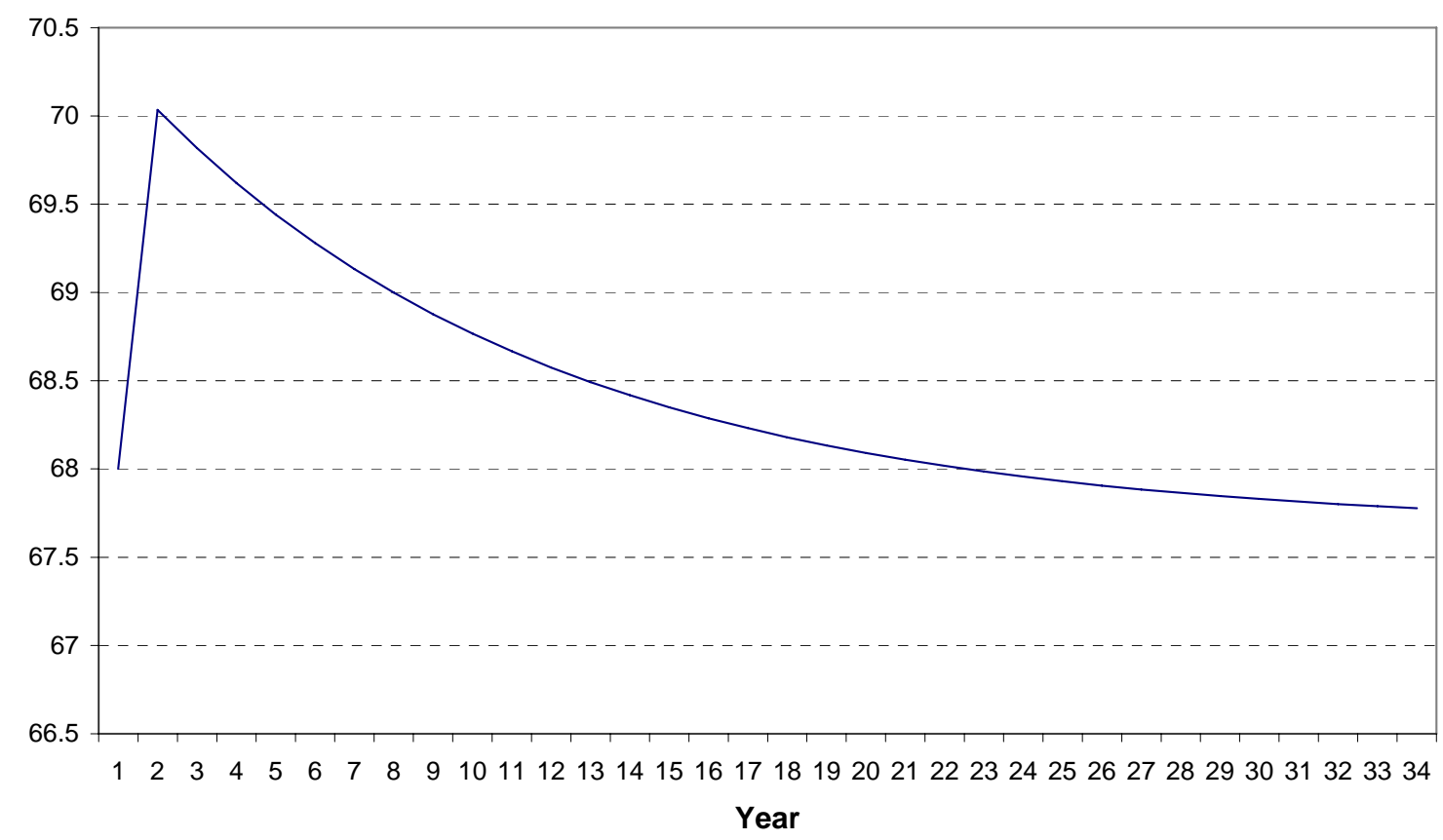




\section{CONCLUding REMARKS}

The Danish flexicurity model has been widely praised for its association with a low unemployment rate and a high standard of social security for the unemployed. The model combines a high degree of labor market flexibility with a high level of social protection. While most European countries are facing chronically high unemployment rates and the needed labor market reforms often face strong political opposition, the flexicurity model looks increasingly attractive to policymakers in Europe.

However, whether the Danish model should and can be adopted by other European countries to reduce unemployment is not obvious. First, Denmark has traditionally had a combination of a flexible labor market and a high level of income protection. Economic performance under this system has varied, as demonstrated by the economic crisis during the early 1980 s and the remarkable labor market performance in recent years. Second, other countries have been able to reduce their high unemployment rates to low levels with rather different social models (e.g., Ireland, Sweden, and the United Kingdom). Finally, generous unemployment benefits often raise moral hazard issues that might hinder effective implementation of the Danish model. In this regard, a strict job search requirement and tight eligibility criteria for unemployment benefits are key.

The Danish model is costly. The tax burden in Denmark is heavy because of the need to finance the country's high spending on labor market programs and unemployment benefits. As most countries that are tempted to adopt the Danish model will typically start from a high unemployment level, a move toward the Danish model will, in the short run, trigger a sharp increase in the cost of unemployment benefits and active labor market policies, thereby widening the tax wedge, with an adverse impact on labor demand and supply. This implies that the Danish model may not be suitable for countries facing high unemployment and budgetary difficulties. Using a calibrated model for France, the paper finds that implementation of the flexicurity model could be costly, and reduction in structural unemployment during the first few years might be limited.

Nonetheless, certain key aspects of the Danish model could usefully be studied and considered by other countries. Among others, they include the various relationships between the population's willingness to accept labor market flexibility, its confidence in a wellfunctioning social safety net, and the accompanying need to develop effective labor market policies in order to avoid high costs and perverse incentives. The Danish government's constant awareness and analysis of the challenges facing the flexicurity model and its ability to respond to them with policy actions are noteworthy in this regard. For instance, since the economic crisis in the early 1980s, reforms have been implemented to shorten the maximum period for participation in active labor market programs and tighten the eligibility criteria for unemployment benefits. 


\section{REFERENCES}

Andersen, T., and M. Svarer, 2006, “Flexicurity—The Danish Labour Market Model,” paper presented at the IMF seminar on Flexicurity held at the Danish Central Bank during the 2006 Article IV mission (draft).

Algan, Y., and P. Cahuc, 2005, “Civic Attitudes and the Design of Labor Market Institutions: Which Countries Can Implement the Danish Flexicurity Model?” IZA Discussion Paper No. 1928 (Bonn: Institut zur Zukunft der Arbeit).

Blanchard, O., and J. Wolfers, 2000, “The Role of Shocks and Institutions in the Rise of European Unemployment: The Aggregate Evidence,” Economic Journal, Vol. 100, No. 462, pp C1-33, (Oxford: Royal Economic Society).

Bredgaard, T., L. Larsen, and P.K. Madsen, 2005, “Two Decades of Structural Reforms in Denmark,” CARMA Research paper: 2005:01.

Gaxier, B., 2006, “Flexicurity and Social Dialogue, European Ways,” paper presented at the DG EMPL Seminar, May.

Gaard, S., 2005, “Labour Market Regimes in Europe and Labour Market Performance,” Finansministeriet Working Paper 13/2005.

Gaard, S., and M. Kieler, 2005, “Two Decades of Structural Reforms in Denmark,” Finansministeriet Working Paper 16/2005.

Madsen, P., 2006, "Flexicurity: A New Perspective on Labor Markets and Welfare States in Europe,” paper presented at the DG EMPL Seminar, May.

OECD, 2005, Employment Outlook (Paris: OECD).

Sapir, A., 2005, “Globalization and the Reform of European Social Models,” Bruegel Policy Brief, Issue 2005/01.

Schubert, C., and H. Martens, 2005, “The Nordic Model: A Recipe for European Success?” EPC Working Paper No. 20.

Wilthagen, T., T. Frank, and H. van Lieshout, 2003, “Towards 'Flexicurity’?: Balancing Flexibility and Security in EU Member States,” paper presented at the $13^{\text {th }}$ World Congress of the International Industrial Relations Association (IIRA), Berlin, September.

Zhou, J., 2006, “Reforming Employment Protection Legislation in France,” IMF Working Paper, WP/06/108 (Washington: IMF). 